\title{
Prognostic Factors of Rheumatic Mitral Stenosis During Pregnancy and Puerperium
}

\author{
Paulo J osé Bastos Barbosa, Antônio Alberto Lopes, Gilson Soares Feitosa, Rosângela Vasconcelos de Almeida, \\ Rosenbert Mamédio da Silva, José Carlos Brito, Maria Lúcia Duarte, \\ Augusto José Gonçalves Almeida
}

Salvador, BA - Brazil

Objective - To identifity characteristics associated with complications during pregnancy and puerperium in patients with rheumatic mitral stenosis.

Methods - Forty-one pregnant women (forty-five pregnancies) with mitral stenosis, followed-up from 1991 to 1999 were retrospectively evaluated. Predictor variables: the mitral valve area (MVA), measured by echocardiogram, and functional class (FC) before pregnancy (NYHA criteria).Maternal events: progression of heart failure, need for cardiac surgery or balloon mitral valvulotomy, death, and thromboembolism. Fetal/neonatal events: abortion, fetal or neonatal death, prematurity or low birth weight $(<2,500 \mathrm{~g})$, and extended stay in the nursery or hospitalization in newborn ICU.

Results - The mean \pm SD of age of the patients was $28.8 \pm 4.6$ years. The eventful and uneventful patients were similar in age and percentage of first pregnancies. As compared with the level $1 M V A$, the relative risk (RR) of maternal events was 5.5 (95\% confidence interval $(C I)=0.8$ 39.7) for level 2 MVA and $11.4(95 \% C I=1.7-74.5)$ for level 3 MVA. The prepregnancy $F C$ ( FC $\geq I I$ and III versus I) was also associated with a risk for maternal events $(R R=2.7$; 95\% CI=1.4-5.3).MVA and FC were not importantly associated with these events, although a smaller frequency of fetal/neonatal events was observed in patients who had undergone balloon valvulotomy.

Conclusion - In pregnant women with mitral stenosis, the MVA and the FC are strongly associated with maternal complications but are not associated with fetal/neonatal events. Balloon mitral valvulotomy could have contributed to reducing the risks of fetal/neonatal events in the more symptomatic patients who had to undergo this procedure during pregnancy.

Key words: pregnancy, mitral stenosis, prognostic factors

Hospital Santa Izabel - Santa Casa de Misericórdia da Bahia

Mailing address: Paulo José Bastos Barbosa - Rua Edístio Ponde, 226/802 41760-310 Salvador, BA - Brazil
In Brazil, rheumatic disease is a major public health problem, affecting children causing as sequelae valvular lesions. The clinical manifestations are relatively early, particularly when compared with data from studies conducted in the US ${ }^{1}$. During pregnancy, mitral stenosis is the most frequent chronic rheumatic orovalvular lesion ${ }^{1-3}$. The poor tolerance of patients with mitral stenosis to pregnancy can be explained by their limited adaptation to the physiological cardiovascular changes occurring during pregnancy (particularly the increase in the plasma volume and in the heart rate) $)^{4,5}$.

Patients with mitral stenosis are found to have frequently overt manifestations of heart failure during pregnancy ${ }^{6-9}$. Even acute lung edema can occur during this period as an initial manifestation of mitral stenosis ${ }^{10,11}$. As a consequence of the heart complications, in these patients with mitral stenosis the mortality rates are higher than those found in healthy pregnant women. The identification of characteristics that indicate the prognosis can help the early selection of patients who need special interventions, in addition to allowing better counseling concerning the risks for those who wish to become pregnant. This study was carried out with the basic objective of identifying the clinical and echocardiographic characteristics related to the occurrence of complications during pregnancy and puerperium in patients with mitral stenosis.

\section{Methods}

We studied 41 patients with mitral stenosis, followedup at the Heart Disease and Pregnancy Section of the Santa Izabel Hospital from March 1991 to March 1999; four patients contributed to the study with two pregnancies each, totaling 45 observations. The patients were referred to our service by the valvulopathy ambulatory clinic or by other services external to Santa Izabel Hospital. Some patients came already with an indication for balloon mitral valvulotomy, but the procedure was only performed after an 
in-house evaluation of the indication, because its protocol imposed restrictions on invasive procedures during pregnancy for patients who remained in functional classes III and IV, with a proper ambulatory clinical treatment. Those patients who remained highly symptomatic were referred preferably for balloon mitral valvulotomy, limiting the indication for heart surgery to those who had contraindications to balloon mitral valvulotomy. The mean gestational age of the 41 pregnant women at the beginning of the follow-up was 6.20 $\pm 2,1$ (median of 5) months.

Although some data were collected retrospectively, information like functional class, drug use, mitral valve area, heart rate, and complications (maternal, fetal, and neonatal) were collected in a systematic manner during the patient follow-up.

The mitral valve area (MVA), measured by the evaluation of the pressure half-time through an echodopplercardiogram, and the functional class before pregnancy, using the criteria of the New York Heart Association, were the most interesting predictor variables. The mitral valve area was divided into three categories: level $1\left(\mathrm{MVA}>1.5 \mathrm{~cm}^{2}\right)$, level $2\left(\mathrm{MVA}>1\right.$ and $\left.\leq 1.5 \mathrm{~cm}^{2}\right)$, and level $3\left(\mathrm{MVA} \leq 1 \mathrm{~cm}^{2}\right)$. Maternal and fetal/neonatal complications occurring during pregnancy, during delivery and up to 30 days postpartum were evaluated. An event was defined as the presence of at least one maternal or fetal/neonatal complication. Maternal complications included: progression of the heart failure, need for heart surgery or balloon mitral valvulotomy, maternal death, lung thromboembolism, peripheral or central nervous system embolic events. Fetal/neonatal complications included: abortion, fetal or neonatal death, prematurity, low birth weight $(<2,500 \mathrm{~g})$, need for extended stay in the nursery or newborn ICU.

As a measure of event frequency, the cumulative incidence or risk was used. It must, however, be pointed out that patients were not necessarily evaluated at the beginning of pregnancy. Thus, the relative risk (RR) estimates are subject to the survival of the patient and maintenance of pregnancy until the time of coming to the cardiology service for follow-up. The descriptive statistics were determined by means of the SPSS frequency, explore, and crosstabs procedures ${ }^{12}$. For the comparison between means, $t$ tests were performed with SPSS ${ }^{13}$. The module Trend from Computer Programs for Epidemiologic Analysis, version 3.0, was used for the evaluation of statistical significance in the tendency of event risks between the categories of predictor variables. The modules RATES 1 of the same software were used for the estimation of the $95 \%$ confidence intervals of the relative risks.

\section{Results}

The mean age \pm SD of the 41 patients on admittance to the study was $28.8 \pm 4.6($ median $=28)$ years (table I). The mean ages were similar between patients with $(29.0 \pm 5.1$; median=28) and without events $(28.6 \pm 4.1$; median=29). Of the 39 patients with known prepregnancy functional class
(FC), 59\% were in FC I, 35.9\% in FC II, and $5.1 \%$ in FC III. FC I was more frequent in uneventful patients $(83.3 \%$ versus $38.1 \%$ ). Based on the electrocardiogram of the first visit, about $92.5 \%$ (37/40) of patients presented with sinusal rhythm, and $7.5 \%$ (3/40) with atrial fibrillation. All three patients with atrial fibrillation were among those with events. Primigravidae occurred in $37.5 \%$ of this sample. In the medical records of six patients, no information was avaiable about the number of pregnancies. The percentage of primigravidae was similar between patients with $(36.8 \%, 7 / 19)$ and without events $(37.5 \%, 6 / 16)$. The mean mitral valve area of the 41 pregnant women was $1.2 \pm 0.4 \mathrm{~cm}^{2}$, being smaller in the eventful group $\left(1.0 \pm 0.2\right.$ vs $\left.1.6 \pm 0.4 \mathrm{~cm}^{2}\right)$.

Table II shows the percentage distribution of maternal and fetal/neonatal complications. The progression to FC III and IV accounted for $48.8 \%$ of maternal complications. The other maternal complications were, by frequency, the following: need for balloon mitral valvulotomy (35.5\%), need for

\begin{tabular}{|c|c|c|c|}
\hline \multicolumn{4}{|c|}{ Table I - Characteristics of the 41 pregnant women } \\
\hline & $\begin{array}{c}\text { General } \\
\mathrm{N}=41\end{array}$ & $\begin{array}{c}\text { Eventful } \\
\mathrm{N}=23\end{array}$ & $\begin{array}{l}\text { Uneventful } \\
\qquad \mathrm{N}=18\end{array}$ \\
\hline \multicolumn{4}{|l|}{ Age (years) } \\
\hline Mean \pm SD & $28.8 \pm 4.6$ & $29.0 \pm 5.1$ & $28.6 \pm 4.1$ \\
\hline Median & 29 & 28 & 29 \\
\hline \multicolumn{4}{|l|}{ Pre-pregnancy FC } \\
\hline I & $59 \%(23 / 39)$ & $38.1 \%(8 / 21)$ & $83.3 \%(15 / 18)$ \\
\hline II & $35.9 \%(14 / 39)$ & $57.1 \%(12 / 21)$ & $11.1 \%(2 / 18)$ \\
\hline III & $5.1 \%(2 / 39)$ & $4.8 \%(1 / 21)$ & $5.6 \%(1 / 18)$ \\
\hline II or III & $41 \%(16 / 39)$ & $61.9 \%(13 / 21)$ & $16.7 \%(3 / 18)$ \\
\hline \multicolumn{4}{|l|}{ Rhythm } \\
\hline Sinusal & $92.5 \%(37 / 40)$ & $87 \%(20 / 23)$ & $100 \%(17 / 17)$ \\
\hline $\mathrm{AF}$ & $7.5 \%(3 / 40)$ & $13 \%(3 / 23)$ & $0 \%(0 / 17)$ \\
\hline \multicolumn{4}{|l|}{ Obstetric history } \\
\hline$\%$ primigravidae & $37.1 \%(13 / 35)$ & $36.8 \%(7 / 19)$ & $37.5 \%(6 / 16)$ \\
\hline \multicolumn{4}{|l|}{$\operatorname{MVA}\left(\mathrm{cm}^{2}\right)$} \\
\hline Mean \pm SD & $1.2 \pm 0.4$ & $1.0 \pm 0.2$ & $1.6 \pm 0.4$ \\
\hline Median & 1.1 & 1.0 & 1.6 \\
\hline $\begin{array}{l}\text { SD- standard dev } \\
\text { fibrillation; MVA }\end{array}$ & $\begin{array}{l}\text { n; FC- functio } \\
\text { tral valve area }\end{array}$ & class $(\mathrm{NYH}$ & AF- atrial \\
\hline
\end{tabular}

\begin{tabular}{|lcc|}
\hline \multicolumn{2}{|c|}{ Table II - Distribution of complications by percentage } \\
\hline Maternal complications & $\mathrm{N}$ & $\%$ \\
\hline Progression to functional class III/IV & $20 / 41$ & 48.8 \\
Balloon mitral valvulotomy & $16 / 45$ & 35.5 \\
Need for heart surgery during pregnancy & $3 / 45$ & 6.7 \\
Embolic phenomenon & $1 / 43$ & 2.3 \\
Maternal death & $1 / 43$ & 2.3 \\
Fetal/neonatal complications & & \\
Low birth weight & $10 / 34$ & 29.4 \\
Premature delivery & $10 / 42$ & 23.8 \\
Extended stay of newborn in & $6 / 42$ & 14.3 \\
nursery or neonatal ICU & & \\
Stillbirth & $2 / 42$ & 4.8 \\
Abortion & $1 / 42$ & 2.4 \\
\hline ICU- Intensive care unit. & & \\
\hline
\end{tabular}


heart surgery during pregnancy $(6.7 \%)$, embolism $(2.3 \%)$, and maternal death $(2.3 \%)$. Low birth weight $(29.4 \%)$ and premature delivery $(23.8 \%)$ were the most frequent fetal/ neonatal complications.

The level 1 mitral valve area was used as a reference for the comparison of maternal and fetal/neonatal events. As compared with level 1 mitral valve area, the relative risk of maternal events was $>5(\mathrm{RR}=5.5$; confidence interval $(\mathrm{CI})$ $95 \%=0.8-39.7)$ for level 2 mitral valve area and $>11(\mathrm{RR}=11.4$; CI 95\%=1.7-74.5) for level 3 MVA; p for the tendency $<0.0005$ (table III). On the other hand, no statistically significant $(\mathrm{p}=0.741)$ tendency was observed in RR for the association between mitral valve area and fetal/neonatal complications (table III). The relative risks of fetal/neonatal events for level $2(\mathrm{RR}=1.5 ; \mathrm{CI} 95 \%=0.4-5.1)$ and level $3(\mathrm{RR}=1.3$; CI $95 \%=0.4-4.1)$ did not exceed 1.5 , and the $95 \%$ confidence intervals comprised the null hypothesis (i.e., $R R=1$ ) therefore corresponding to values of $\mathrm{p}>0.05$. Similar to that observed for MVA, the prepregnancy FC (FC II or III vs. FC I) showed a statistically significant $(\mathrm{p}<0.05)$ association with maternal events $(\mathrm{RR}=2.7$; CI95\%=1.4-5.3) (Table IV). The FC was not associated with fetal/neonatal events $(\mathrm{RR}=1.1$; CI $95 \%=0.5-2.5)$. An analysis of the restricted group of women with mitral valve area of $\leq 1.5 \mathrm{~cm}^{2}$ (Fig. 1) showed that, of the 11 patients kept under clinical treatment, $5(45.4 \%)$ had fetal/ neonatal complications. On the other hand, of the 16 patients who underwent balloon mitral valvulotomy, only 3 $(18.7 \%)$ had complications of the same kind.

\section{Discussion}

According to our data, pregnant women with mitral stenosis still are at a relatively high risk of experiencing maternal complications. The results shown are consistent with those reported by other authors ${ }^{6,9,14}$. The association of the prepregnancy functional class with the risk of maternal events draws the attention to the possibility of reducing

\begin{tabular}{|c|c|c|c|c|}
\hline \multicolumn{5}{|c|}{$\begin{array}{l}\text { Table III - Association between valve area and events, taking the } \\
45 \text { pregnancies into account }\end{array}$} \\
\hline \multicolumn{5}{|c|}{ Maternal events } \\
\hline \multicolumn{5}{|c|}{ Events } \\
\hline MVA & Yes & No & $\%$ of events & $\mathrm{RR}(\mathrm{CI} 95 \%)$ \\
\hline Level 1 & 1 & 11 & 8.3 & 1.0 (reference) \\
\hline Level 2 & 5 & 6 & 45.5 & $5.5(0.8-39.7)$ \\
\hline Level 3 & 18 & 1 & 94.7 & $11.4(1.7-74.5)$ \\
\hline \multicolumn{5}{|c|}{ Value of $\mathrm{p}$ for tendency $<0.0005$} \\
\hline \multicolumn{5}{|c|}{$\begin{array}{l}\text { Fetal/neonatal events } \\
\text { Events }\end{array}$} \\
\hline MVA & Yes & No & $\%$ of events & $\mathrm{RR}(\mathrm{CI} 95 \%)$ \\
\hline Level 1 & 3 & 9 & 25.0 & 1.0 (reference) \\
\hline Level 2 & 4 & 7 & 36.4 & $1.5(0.4-5.1)$ \\
\hline Level 3 & 6 & 13 & 31.6 & $1.3(0.4-4.1)$ \\
\hline \multicolumn{5}{|c|}{ Value of $\mathrm{p}$ for tendency $=0.741$} \\
\hline
\end{tabular}

\begin{tabular}{|c|c|c|c|c|}
\hline \multicolumn{5}{|c|}{$\begin{array}{l}\text { Table IV - Association between pre-pregnancy functional class and } \\
\text { events, taking the } 45 \text { pregnancies into account }\end{array}$} \\
\hline \multicolumn{5}{|c|}{ Maternal events } \\
\hline & & & & \\
\hline $\mathrm{FC}$ & Yes & No & $\%$ of events & RR (IC 95\%) \\
\hline I & 7 & 17 & 29.2 & 1.0 (reference) \\
\hline II ou III & 15 & 4 & 79.9 & $2.7(1.4-5.3)$ \\
\hline \multicolumn{5}{|c|}{ Fetal/neonatal events } \\
\hline FC & Yes & No & $\%$ of eventos & RR (IC 95\%) \\
\hline I & 8 & 16 & 33.3 & 1.0 (referência) \\
\hline II ou III & 7 & 12 & 36.8 & $1.1(0.5-2.5)$ \\
\hline
\end{tabular}

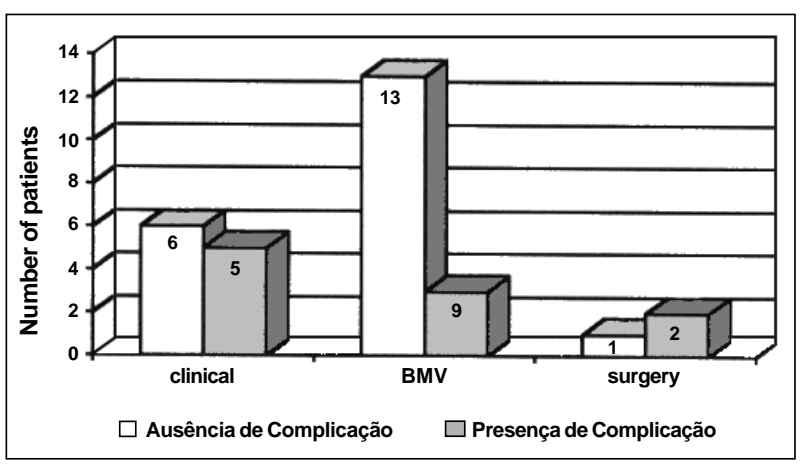

Fig. 1 - Fetal/neonatal complications among women with mitral stenosis with a mitral valve area $\leq 1.5 \mathrm{~cm}^{2}$, according to the treatment adopted during pregnancy: clinical, treatment, balloon mitral valvulotomy or surgery.

these complications in pregnant women with mitral stenosis by means of early interventions aimed at improving their functional class. The mitral valve area was also strongly and significantly associated with the risk of maternal events. If the mitral valve area was the only determining risk factor for events in these patients, the correction of high-degree stenosis should correspond to a pronounced reduction of the occurrence of maternal complications during pregnancy and puerperium. Based on this assumption and with the purpose of reducing the gestational risks, interventional treatment (balloon mitral valvulotomy or surgery) prior to conception has been recommended to patients with severe mitral stenosis who wish to get pregnant ${ }^{15}$. However, like in the present study, usually women with mitral stenosis are referred for cardiological follow-up only after the beginning of pregnancy. Facing these facts and the low incidence of complications observed when the balloon mitral valvulotomy technique is used during pregnancy ${ }^{16-23}$, this procedure should be seriously considered for the treatment of pregnant women with mitral stenosis and a greatly reduced mitral valve area, independently of their functional class, particularly if we take into account that acute lung edema can be the first clinical manifestation of mitral stenosis during pregnancy ${ }^{10,11}$.

Unfortunately, we did not have the opportunity to eva- 
luate the influence of important covariables on the associations investigated in this study. The magnitude of increase of the plasma volume and of the heart rate, which occur physiologically during pregnancy, are factors worth being taken into consideration in view of their potential influence on the presentation of symptoms in pregnant women with mitral stenosis ${ }^{3,5}$. So, it is possible that the analysis of hemodynamic variables measured by means of echocardiography, such as the mitral transvalvar gradient and pulmonary artery pressure, reflect the interaction between the mitral valve area and physiological cardiocirculatory alterations. The evaluation of such factors might help to explain the fact that patients with moderate mitral stenosis have a worsening of their functional class whereas others with severe stenosis tolerate pregnancy well.

As can be seen, approximately $45 \%$ of patients in this study required interventional treatment $(35.5 \%$ balloon mitral valvulopathy and $6.7 \%$ heart surgery). This percentage is considerably higher than that reported by Avila et al ${ }^{6}$, by whose protocol functional class III/IV patients were hospitalized for relatively long periods of time, some cases for up to 14 weeks, to intensify the therapeutic measures. By the protocol adopted by us, even though patients in functional class III/IV were hospitalized for therapeutic optimization, the criterium for indication of intervention treatment was the persistence in functional class III or IV despite outpatient treatment (provided they were receiving a therapy considered appropriate). The conduct adopted with the patients of this study can be justified by taking the following points into account: 1) the good results obtained by our team with the balloon mitral valvulopathy technique, a consistent experience with the low incidence of maternal and fetal complications related to this procedure, also reported by other investigators ${ }^{16-24} ; 2$ ) the high cost of a long hospitalization of patients; 3 ) the risk of keeping patients with a relatively severe condition on outpatient follow-up; 4) the patients' low socioeconomic level, making compliance with therapeutic decisions difficult.

According to the results of this study, the mitral valve area and the functional class were not significantly associated with fetal/neonatal complications, a finding that may be explained in part by the high percentage of premature births and low birth weights, even among patients with less severe heart diseases (Tables III and IV), as reported by other authors ${ }^{25,26}$. In addition to this, it must be considered that possibly the performance during pregnancy of balloon mitral valvulopathy on $16(35.5 \%)$ patients who were highly symptomatic contributed to a reduction in the incidence of fetal/neonatal events in this group of patients (fig. 1).

Although this study shows interesting findings, limitations of a methodological nature cannot be ignored. Among them are inter-observer disagreement and the possibility of error in the measuring of the mitral valve area ${ }^{27}$. It is very unlikely though that the probability of an incorrect diagnosis could have been different (i.e., of differential or nonrandom type) in the group of eventful and of uneventful patients. Actually, the existence of a differential (or random) error would tend to reduce the strength of the association between mitral valve area and events ${ }^{28}$. Therefore the real association between mitral valve area and events during pregnancy and puerperium may be even stronger than that found in our study. It is important to observe that, in spite of the relatively small size of our sample, a statistically significant tendency between the mitral valve area and events was detected. It is also important to consider that not all patients were examined at the beginning of their pregnancy. Thus the validity of the associations is restricted to the premise that the findings during pregnancy represent the patient's condition at the beginning of pregnancy. Should these results be generalized with regard to other populations, the local conditions of the study should also be taken into account. The Santa Izabel Hospital is a referral center in cardiology, which must have contributed to the selection of a sample with more severely affected patients.

Despite its limitations, the presented results and the proposed hypotheses can represent a basis for the development of prospective investigations, for a better understanding of the factors related to the prognosis for a pregnant woman with mitral stenosis. These results confirm the conclusions of the II Brazilian Consensus on Heart Disease and Pregnancy. According to this Consensus, the following factors should be seen as risk factors for complications during pregnancy in women with mitral stenosis: worsening of functional class, atrial fibrillation, frequent supraventricular extrasystoles, right atrial surcharge and left atrium $>45 \mathrm{~mm}^{29}$. The Consensus stresses the fact that a numerical cut-off line of the echocardiographic parameters, which are correlated with evolution during pregnancy, has not yet been established. It points out though that a mitral valve area $<1.5 \mathrm{~cm}^{2}$ is associated with a higher maternal morbidity, but that, however, it cannot be used separately for the determination of a therapeutic conduct, a correlation with the clinical data being mandatory.

Although this study was not conducted with the primary objective of testing the effectiveness of therapeutic interventions, the experience acquired in the Heart Disease and Pregnancy Sector of the Santa Izabel Hospital supports the idea of a greater use of balloon mitral valvulotomy in pregnant women with mitral stenosis. Another research work ${ }^{30}$, also conducted in our population, showed that in patients with mitral stenosis the echocardiographic score is usually very low, the mean being at 7 points. Under these circumstances, in the absence of pregnancy, balloon mitral valvulotomy proves to be, as compared with surgical treatment, highly effective and of low risk for complications ${ }^{24,31-33}$. Similarly, during pregnancy, this procedure proved to be effective and safe both for the mother and for the fetus. Thus, once mitral valve disease was identified as a major risk factor for maternal complications and balloon mitral valvulotomy is suggested to reduce the risk of fetal complications, it seems sensible to us to use this procedure in pregnant women with severe mitral stenosis, regardless of their functional class. 


\section{References}

1. Avila WS, Grinberg M. Gestação em portadoras de afecções cardiovasculares. Experiência com 1000 casos. Arq Bras Cardiol 1993; 60: 5-11.

2. MacFaul PB, Dorman JC, Lamki H, Boyle D. Pregnancy complicated by maternal heart disease. A review of 519 women. Br J Obstet Gynecol 1988; 95: 861 .

3. Guleria R, Vasisht K, Dhall GI, Grover A, Wahi PL. Pregnancy with heart disease. Experience at Postgraduate Institute of Medical and Research, Chandigarh. J Assoc Physicians India 1990; 38: 902-6.

4. Ueland K, Metcalfe J. Circutatory changes in pregnancy. Clin Obestet Gynecol 1975; 18: 41-60.

5. Clapp III JF. Maternal heart rate in pregnancy. Am J Obstet Gynecol 1985; 15 659-60.

6. Avila WS, Grinberg M, Décourt LV, Bellotti G, PileggiF. Evolução clínica de portadoras de estenose mitral no ciclo gravídico-puerperal. Arq Bras Cardiol 1992; 58: $359-64$

7. Avila WS. Fatores de prognóstico em portadoras de estenose mitral no ciclo gravídico-puerperal. Tese de Doutorado. São Paulo: Faculdade de Medicina da Universidade de São Paulo, 1991

8. Andrade J. A doença reumática no ciclo gravídico-puerperal. Tese de Doutorado. São Paulo: Faculdade de Medicina da Universidade de São Paulo, 1981.

9. Born D. Insuficiência e estenose mitral na gravidez: análise de variáveis maternas e do concepto. Tese de Doutorado. São Paulo: Escola Paulista de Medicina Universidade Federal de São Paulo, 1996

10. Franken RA. Edema agudo de pulmão na gravidez. Arq Bras Cardiol 1986; 47: 413-5.

11. Morley CA, Lim BA. The risks of delay in diagnosis of breathlessness in pregnancy. Br Med J 1995; 311: 183-4.

12. Norusis MJ. SPSS for Windows: Advanced Statistics, release 6.0, SPSS Inc, Chicago, IL, 1993.

13. Gahlinger PM, Abramson JH. Computer Programs for Epidemiologic Analysis: PEPI. Stone Mountain: USD Inc, 1995.

14. Al Kasab SM, Sabag T, Al Zaibag M, et al. Beta-adrenergic receptor blockade in the management of pregnancy women with mitral stenosis. Am J Obstet Gynecol 1990; 163: (1 Pt 1): 37-40.

15. Braunwald E. Valvular Heart Disease. In: Braunwald E. Heart Disease. A Textbook of Cardiovascular Medicine. $5^{\text {th }}$ Edition. Philadelphia: WB Saunders, 1997: 1014.

16. Mangione JA, Ariê S, Oliveira AS, et al. Valvuloplastia mitral com cateter balão em pacientes grávidas. Arq Bras Cardiol 1989; 52: 99-101.

17. Esteves CA, Ramos AIO, Braga SLN, Harrison JK, Sousa JEMR. Effectiveness of percutaneous baloom mitral valvulotomy during pregnancy. Am J Cardiol 1991 68: $930-4$.

18. Drobinski G, Fraboulet $\mathrm{P}$, Montalescot $\mathrm{G}$, et al. Valvuloplastie mitrale au quatriè- me mois de grossesse. Protection foetale par un manteau de plomb. Arch Mal Couer 1991; 84: 249-51

19. Grupta A, Lokhandwala YY, Satoskar PR, Salvi VS. Balloon mitral valvulotomy in pregnancy: maternal and fetal outcomes. J Am Coll Surg 1998; 187: 409-15.

20. Patel JJ, Mitha AS, Hassen F, et al. Percutaneous balloon mitral valvulotomy in pregnancy patients with tight pliable mitral stenosis. Am Heart J 1993; 125 : 1106-9.

21. SouzaJAM. Valvuloplastia mitral percutânea por cateter-balãoem gestantes com estenose mitral. Avaliação dos resultados e comparação da evolução obstétrica com gestantes submetidas a comissurotomia mitral cirúrgica. Tese de Doutorado. Escola Paulista de Medicina - Universidade Federal de São Paulo. São Paulo, 1996.

22. Dunn B, Duran CG. Balloon valvotomy for pregnant patients with severe piable mitral stenosis using the Inoue technique with total abdominal and pelvic shielding. Am Heart J 1992; 124: 1558-61.

23. Andrade JA. Gestante cardíaca em serviço de saúde. O papel da valvuloplastia por cateter-balão, em mulheres portadoras de estenose mitral reumática na gestação. Tese de Livre-Docência. Faculdade de Saúde Pública da Universidade de São Paulo. São Paulo, 1995.

24. Brito JC, Carvalho H, Braga J, et al. Valvuloplastia mitral com cateter-balão de Inoue - análise de 112 casos. Arq Bras Cardiol 1993; 61: 213-16.

25. Ueland K, Metcalfe J. Acute rheumatic fever in pregnancy. Am J Obstet Gynec 1966; 95: 586-7.

26. Faccioli R. Área valvar mitral estenótica em gestantes portadoras de doença reumática - correlação com o prognóstico perinatal. Tese de Doutorado. Faculdade de Medicina da Universidade de São Paulo. São Paulo, 1989.

27. Loyd D, Ask P, Wranne B. Pressure half-time does not always predict mitral valve area correctly. J Am Soc Echocardiogr 1998; 1: 313

28. Henneekens CH, Buring JE. Epidemiology in Medicine. Boston/Toronto: Little, Brown and Co., 1987: 276

29. Consenso Brasileiro sobre cardiopatia e gravidez. Arq Bras Cardiol 1999; 72(supl III).

30. Feitosa GS, Leite M, Tadeu E, et al. Escore ecocardiográfico em estenose mitral Arq Bras Cardiol 1991; 57(supl C): 155

31. Turi ZG, Reyes VP, Raju BS, et al. Percutaneous balloon versus surgical closed comissurotomy for mitral stenosis. A prospective, randomized trial. Circulation 1991; 83: 1179-85

32. Wilkins GT, Weyman AE, Abascal VM, Palacios IF, Block PC. Percutaneous mitral valvotomy. An analysis of echocardiographic variables related to outcome and mechanism of dilatation. Br Heart J 1988; 60: 299.

33. Block PC, Palacios IF. Aortic and mitral valvuloplasty: The United States experience. In: Topol EJ (ed). Textbook of Interventional Cardiology. Philadelphia: WB Saunders, 1994: 1189. 